\title{
GAUVAIN O LA DEGRADACIÓN DEL HÉROE
}

ALICIA YLLERA

UNED

En el Tristan en prose, Tristan declara «je sai bien que messire Gauvains est plains de felonie coverte» (ed. Curtis I, 417). Tan adversa consideración de uno de los más antiguos personajes del mundo artúrico es el resultado de una evolución ocurrida en determinados textos, especialmente en textos continentales. Las palabras de Tristan contrastan fuertemente con la presentación que de él hacía Wace, cuando, hablando de Gauvain y de Hoel de Bretaña, declaraba:

Tel dui vasal ne furent ainz

De bonté ne de corteisie

$\mathrm{Ne}$ de Pris de chevalerie.

(Brut, vv. 4202-4204)

Eco de las palabras de Geoffrey de Monmouth, cuando decía que «Hoelus igitur et walwanius, quibus meliores praeterita saecula non genuerant» ( $\$ 173)$. Aunque esta degradación ha sido ya observada, no parece ocioso replantearla, teniendo en cuenta que algunos textos eligen como prototipo de la felonía a una de las figuras artúricas más cargadas de significado mítico ${ }^{1}$.

1 Se han tenido en cuenta, para elaborar este trabajo, los textos citados en la bibliografia; salvo indicación contraria, se cita por la obra precedida de un asterisco; en las citas de Malory la primera cifra remite al libro y la segunda al capítulo. Se emplean, para los nombres de los perso- 
La degradación del personaje, convertido en prototipo de la felonía y de la traición, es evidente en el Tristan en prose, pero no es exclusiva de este texto. No hay que olvidar, por otra parte, la extraordinaria importancia de esta obra, que contaminó a las versiones post-vulgatas del Lancelot-Graal, fuente de la mayoría de las adaptaciones extranjeras. Frente a esta degradación, que se intentará analizar, existe una evolución inversa, hacia un progresivo ennoblecimiento, hacia una mayor espiritualización, particularmente visible en el más bello poema sobre el sobrino de Arturo, la obra en verso inglesa Sir Gawain and the Green Knight.

\section{Gauvain y el MUNDO aRTURf́co}

Pueden distinguirse diversas etapas dentro de la materia artúrica, aunque no se sucedan en un orden estrictamente cronológico.

Un primer momento estaría representado por Geoffrey de Monmouth y Wace. Es la etapa de la historia legendaria. Lo que interesa destacar es la labor conquistadora y civilizadora de Arturo y de su corte. El rey se presenta como un nuevo Alejandro que reúne bajo su mando las Islas Británicas, conquista la Galia y, cuando va a marchar sobre Roma, ve deshechas sus esperanzas de dominar al Imperio por la traición de su sobrino Mordret. La ruina del reino se debe a una traición familiar, como también la derrota en la Chanson de Roland. Sus enormes conquistas se acompañan del esfuerzo por extender las virtudes civilizadoras del Cristianismo.

En un segundo momento, la corte de Arturo es el lugar de las aventuras caballerescas destinadas a conseguir la gloria y el amor. Se perfila un importante individualismo en la lucha del caballero. Arturo es el centro de la corte pero presenta un carácter estático y hierático. $\mathrm{El}$ gran héroe es Gauvain, que sustituye a Arturo como guerrero, del mismo modo que es posible que Gauvain sustituyese a Arturo como mito solar ${ }^{2}$. La Tabla Redonda es un lugar edénico, un espacio en el que se ha abolido el tiempo ${ }^{3}$. Es el mundo de Chrétien de Troyes, aunque el autor rehuye elegir a Gauvain como protagonista de

najes, los más frecuentes en los textos franceses pero se respetan los nombres empleados en los textos ingleses cuando se trata de una cita o referencia a éstos.

2 Posteriormente se aludirá a los caracteres de Gauvain en cuanto héroe solar.

${ }^{3}$ Los héroes artúricos no envejecen, como tampoco los héroes homéricos. 
sus obras 4 . Sin duda este personaje, más rico en tradición legendaria y más conocido, le permitía crear menos libremente. Dejando de lado a Chrétien de Troyes, que elige a personajes secundarios o inventados para encarnar las principales aventuras de sus relatos, pertenecen también a esta misma etapa una serie de poemas, en muchos de los cuales pervive el protagonismo de Gauvain': Le Chevalier à l'épée, La Mule sans frein, La Vengeance Raguidel, $L$ Âtre Périlleux, etc. Esta etapa se prolonga a lo largo de todo el siglo XIII e incluso en el XIV (entonces fuera de Francia), en competencia con la tendencia siguiente.

Hacia 1200, con Robert de Boron, se inicia el gran movimiento de cristianización del mundo artúrico. El ideal social y mundano de la Tabla Redonda se sustituye por un ideal cristiano que caracteriza a esta tercera etapa. A ella pertenecen los textos de mayor difusión, traducidos a la mayoría de las lenguas europeas. Paradójicamente, la materia artúrica se divulgó bajo la forma de una reformulación que alteraba esencialmente su sentido. Objetos cargados de una simbología mundana se sustituyen por objetos con significado cristiano o se duplican los objetos. De este modo, si la espada Excalibur, "gladio optimo et in insula Avallonis fabricato", como dice Geoffrey de Monmouth (\$147) -rasgo que recoge Wace (vv. 739-742) - conserva su importancia, en la Queste del Saint-Graal (202-210, 223, 227-228), se ve sustituida por la espada de David que recibe Galaad. Arturo recupera parcialmente su actividad primitiva; participa en torneos, aventuras y luchas, sobre todo

4 S6lo si se acepta que Le Conte du Graal era originariamente un conjunto de dos obras torpemente unidas por un copista puede pensarse que Chrétien eligió a Gauvain como protagonista de una obra. Sin embargo, nos inclinamos a considerar Le Conte du Graal como una única obra, en la que Chrétien practica su procedimiento preferido de la contraposición de las aventuras de dos caballeros, como se verá posteriormente. Fue Martín de Riquer (1957, 1957-1958) quien, reelaborando una hipótesis de G. Grober, lanzó la tesis de la doble obra, que posteriormente ha sido defendida, entre otros, por D.D.R. Owen (1968, VII). Sostienen la teoría de la unidad de la obra: J. FrapPIER (1958, 1960, 1972: 60ss), E. KOHLER (1974:311), P. LE RIDER (1978: 11-15, $357-$ 358), Guy Vial (1987: 9), etc. Para evitar una extensa enumeración de estudios sobre la cuestión remitimos a KöHLER para los trabajos de refutación aparecidos antes de la segunda edición de su obra.

5 Busby observa que, incluso en las obras en las que Gauvain es el protagonista, su triunfo nunca es completo, ya sea porque se desvía de su demanda para buscar aventuras secundarias, ya sea porque requiere a otro personaje para llevar a cabo la acción. Distingue quest y adventure y anade: «However, from the point of view of romance narrative structures and types, the fact that Gauvain either fails his quest, or is shown only taking part in adventures, disqualifies him from the category of the hero (1980: 389-391). No se tiene en cuenta, en este trabajo, el Tristan en prose. Anteriormente Marx (1959) analizaba, en diversos textos, la «quête manquée» de Gauvain. 
en el Perlesvaus, en la Mort d'Arthur o en la versión de Malory. La pérdida del reino no se debe ya sólo a la traición familiar sino que es fruto de las rencillas internas y sobre todo del pecado sexual: el incesto de Arturo con su hermana, por el que engendra a Mordret ${ }^{6}$, y los amores de Lancelot y Guenièvre. Como en la leyenda del conde don Julián, la pérdida del reino es fruto de la lujuria.

Tradicionalmente se considera que la degradación de Gauvain se produce en esta tercera etapa. Posiblemente habría que ver en el mismo Chrétien de Troyes la génesis última de la evolución sufrida por el personaje en un gran número de textos ${ }^{7}$, especialmente en los textos en prosa, los textos que pretenden presentarse como «historia» más que como mera «leyenda poética». Esta evolución del personaje parece estar vinculada al tratamiento continental de la materia artúrica en las obras en prosa, pero también a determinadas características del personaje.

\section{La eVolución del personaje de Gauvain}

Gauvain es uno de los personajes artúricos de los que tenemos una más antigua documentación. Antes de que Geoffrey de Monmouth popularice su imagen, habla de él Guillermo de Malmesbury (1125). Señala que su tumba se descubrió en el condado de Pembroke y que era sobrino de Arturo y gran guerrero, pero se ha apuntado que es posible que lo confunda con el rey Maelgun (G. Paris, 1888: 29-30). Su celebridad era incluso anterior a esta mención incierta puesto que, a principios del siglo XII, está atestiguado su nombre en Italia (Loomis, in Loomis, ed., 1959: 60) y la escultura de Modena (entre 1099 y 1120) le hace participar en la resolución del rapto de Guenievre mientras que no aparece Lancelot ${ }^{8}$. Se duda acerca de su prototipo

6 Para Monmouth y Wace, Mordret es meramente el sobrino de Arturo; en el Lancelot-Graal es su hijo incestuoso, como también en Malory.

7 Al analizar Le Conte du Graal, ya Le Rider (1978: 344) hablaba del malestar que producen los episodios referidos a Gauvain puesto que Chrétien no hace que su héroe responda a la acusación de homicidio. Añade (369): «Il [Chrétien] a fait le procès de Gauvain et ne lui a accordé que dans la mort la disculpation par l'exploit mythiquen.

${ }^{8}$ La escena representada en el portal norte de la catedral de Modena parece aludir a una versión arcaica del rapto de Guenièvre; los nombres de los personajes están grabados en la piedra y entre ellos no figura Lancelot pero si Galvaginus (Gauvain), Isdernus (Ider), Arturo, Che (Keu), 
galés ${ }^{9}$ pero parece seguro que tomó originariamente ciertos rasgos del héroe irlandés Cuchulainn, sobrino de Conchobar, como él lo es de Arturo. Es posible que Gauvain sustituyese a Cuchulainn en algunas aventuras en las que posteriormente será sustituido por Lancelot, Perceval o Galaad ${ }^{10}$.

Gauvain es un personaje indispensable en esa corte de Arturo «qui tant fu loee et prisiee" (Chevalier à l'épée, v. 22), protagonista de un cierto número de obras en verso, en las que es considerado como el mejor caballero de la corte: Le Chevalier à l'épée, La Mule sans frein, L'Âtre Périlleux, La Vengeance Raguidel, Humbaut, etc., Sir Gawain and the Green Knight, y otros poemas no franceses. Pero, fuera de estos textos, se aprecia una sensible evolución del personaje hacia una progresiva degradación.

En Geoffrey de Monmouth, sin ser el principal compañero de Arturo, se alude al matrimonio de su padre Lot, hermano de Urien y Anguisel, con la hermana del rey $(\$ 139, \S 152)$. Cuando Arturo conquista Noruega para darla

etc. Estos cuatro caballeros liberan a una dama. Una versión muy cristianizada del rapto de Guenièvre nos la proporciona la Vita Sancti Gildae, compuesta por el clérigo galés Caradoc de Llancarvan, probablemente antes de 1136 y, en último término, no después de 1160 . Se narra en ella cómo Melwas, rey del país del verano, raptó a Guennuvar, esposa del rey Arturo, llevándola a la Ciudad de Cristal, pero acabó devolviéndola, gracias a la intervención del abad de Glastonbury (Frappier, 1957: 136-137; Loomis, en Loomis, ed., 1959: 52-63). Basándose en este testimonio, se ha supuesto que inicialmente es Arturo el que rescataba a Guenièvre (G. Paris, 1883: 459-534; Bruce, 1923 I: 204-205). Aunque no existen pruebas de que originariamente fuese Gauvain el héroe de esta aventura, la escultura de Modena refleja una tradición antigua en la que Gauvain participaba en el rescate de la reina y no aparecía Lancelot. Existen dos hipótesis acerca de los amores de Lancelot-Guenièvre: unos autores han supuesto, sin excesivas pruebas, que originariamente correspondía a Gauvain el papel de sobrino-amante (Marx, 1952: 66, etc.), para otros estos amores se deberían a la influencia de Tristan e Iseo (Weston, 1901: 207). Aunque en las formas arcaicas de la leyenda está atestiguada la traición del sobrino Mordret, no existen pruebas suficientes para afirmar que en un principio fuese Gauvain el amante de la reina.

${ }^{9}$ Se supuso en un principio que su prototipo galés era Gwalchmai pero se apuntó también que Gwalchmai podría ser una adaptación galesa de Gauvain (Cf. Bruce 1923: 21, n. 4). Loomis (1949: 147-152) propuso como prototipo Gwrvan Gwaltt-Avwyn; la confusión entre los nombres Gwri, Gware, Gwrvan Gwallt-a(d)vwyn y Gweir hijo de LLwch explicaria las relaciones entre Cuchulainn y Gauvain: «The connection between Cuchulainn and Gauvain through the intermediate Gwri or Gweir is established by the fact that Cuchulainn was the son of the Irish god Lug Lonnbemnech (later form Lugh Loinnbheimionach), Gweir was the son of Llwch or Lloch Llawwynnyawc, and Guahries and his brother (or rather his alter ego) Gauvain were sons of Loth, who, according to the best reading of Erec, verse 1737, was an "Irois"».

10 "Gawain es el héroe original de muchas aventuras posteriormente atribuidas a Lanzarote, Perceval y Galahad» (Campbell, 1959: 295, n. 14). Sin embargo, aunque es atractiva la hipótesis de que en un principio las aventuras del Graal o del rescate de la reina fueran aventuras de Gauvain [como defendió Weston, 1897: 419; etc., y refutaron Bruce, 1923 I: 216, n. 41; Marx, 1952: 205-206; 1959: 415-416; etc., este último para la aventura del Graal], no existen pruebas definitivas que permitan afirmarlo tajantemente. 
como reino a Lot, Gauvain tiene doce años y ha sido enviado a Roma al servicio del papa Sulpicio (\$154). Posteriormente, se distingue, ya adulto, como mensajero ante los romanos y en la lucha contra ellos (\$166-175). Se enfrenta incluso con Lucio Tiberio, jefe de los romanos, pero no corresponde a Gauvain el honor de acabar con él sino que muere por una lanza anónima $(\$ 173$, $\$ 175$ ). El autor no se detiene tampoco en su muerte en la lucha contra Mordret (\$177). Hoel de Armórica ocupa un lugar mucho más destacado junto a Arturo. Persiste su estatuto en Wace, donde los principales compañeros de Arturo son también Keu y Bedoer. Sin embargo, estos textos, con su alusión a su infancia en Roma, suponen una serie de leyendas en torno al personaje, en las que presenta uno de los rasgos más persistentes del héroe tradicional: el exilio juvenil, la separación de los suyos. En textos posteriores (Enfances Gauvain) se atestiguan otros rasgos típicos, como son el nacimiento ilegítimo, que conlleva la exposición del recién nacido y su salvación por el que será su padre aparente que, en este caso, le dará su nombre ${ }^{11}$.

En el Lai de Lanval de Marie de France es «li francs, li pruz,/ ki tant se fist amer de tuz» (vv. 227-228).

Del conjunto de personajes que Chrétien de Troyes hereda de Geoffrey y de Wace, elige a algunos, prescinde de otros y crea nuevos personajes, orientando toda la evolución posterior de la materia artúrica. Sin duda, en el proceso de racionalización al que somete la tradición heredada, estorba el personaje de Gauvain, cargado de alusiones míticas, como muestra el ejemplo de sus fuerzas crecientes ${ }^{12}$. Tal vez por ello nunca lo elige como protagonista de sus obras aunque lo presenta como el personaje principal de la corte de Arturo, mientras que desaparece Bedoer, el inseparable compañero del rey en Geoffrey o Wace. Existe también cierta evolución en el mismo Chrétien. Gauvain es el caballero preferido de Arturo y el mejor caballero de la corte en Erec et Enide, en Cligès o en Le Chevalier au lion:

car n' avoit baron en sa cort

plus vaillant, plus hardi, plus preu,

$"$ En el Perlesvaus se recoge también una versión de la leyenda de la concepción adulterina y del nacimiento e infancia de Gauvain. Arturo y Gauvain llegan a un castillo. En la capilla descubren unas pinturas que refieren la historia de Gauvain, según les explica un clérigo. Este castillo perteneció al que, encargado de hacer desaparecer al niño, lo hizo criar y se lo dejó a su muerte (7288-7337).

12 Se aludirá posteriormente a ellas. 
fors Gauvain, son tres chier neveu:

a celui ne se prenoit nus; aprés celui prisoit li plus

Erec et plus le tenoit chier

que nes un autre chevalier.

(Erec et Enide, vv. 2230-2236)

Los protagonistas se enfrentan con él pero se suspende el combate, evitando conceder el premio a uno u otro. En cambio, en Le Chevalier de la Charrette o en Le Conte du Graal, los protagonistas superan a Gauvain. En el primero, Gauvain rehusa montar sobre la carreta, juzgándolo demasiado deshonroso, y, para perseguir al raptor de la reina, elige el "puente bajo el agua», menos peligroso que el «puente de la espada», que toma Lancelot. Además no logra superar esta prueba y han de ir a rescatarlo.

Conserva la superioridad de la que gozaba en Erec et Enide en los poemas episódicos en verso a los que antes se aludió, y muy especialmente en el Sir Gawain and the Green Knight. Incluso en un poema alemán, Diu Krône de Heinrich von dem Türlin (principios del siglo XIII) es Gauvain y no Perceval el que descubre los misterios del Graal. G. Paris (1888: 42-44) pensaba que era una invención del autor alemán no inspirada en el texto francés pero es posible que existiesen leyendas o textos en los que el Graal fuese una aventura de Gauvain. Mantiene su posición privilegiada en la Primera Continuación del Conte du Graal (llamada Continuación Gauvain) y en el Perlesvaus. En la Continuación es el prototipo de la cortesía, modelo de la caballería y objeto de numerosas alabanzas. En Perlesvaus es uno de los tres mejores caballeros, junto a Lancelot y Perlesvaus. A diferencia de la Queste del Saint-Graal, participa más activamente que Lancelot en la búsqueda del Graal, pues consigue la espada con la que decapitaron a san Juan Bautista, pero, por sus pecados, se ve superado por Perlesvaus.

Lancelot supera a Gauvain en el Lancelot en prose; participa del alimento que distribuye el Graal mientras que el sobrino de Arturo se distrae con la belleza de la doncella que lleva el vaso (II: 377 ). Bohort logra incluso demostrar, por su victoria con las armas sobre Agravain, la superioridad de Lancelot (II: 179-182) pero Gauvain sigue ocupando un lugar predominante en la corte y se distingue por su sentido común y nobleza. Palidece su estrella en la Queste del Saint-Graal; aunque fue él el primero en hacer el juramento de partir en su búsqueda, no encuentra aventuras porque ahora las aventuras se han convertido en signos (160-161). Se ve castigado por su vida frívola pero es también tachado de «desleal» (97). Lancelot sigue dominando en La 
Mort d'Arthur pero Gauvain es una figura noble, amigo de Lancelot, como era siempre, en los viejos relatos de Chrétien, amigo del protagonista; sólo cuando Lancelot mata, sin reconocerlo, a su hermano Gaheriet, al salvar a la reina de la hoguera (\$93-94), se deja llevar por sus deseos de venganza e instiga al rey a luchar contra Lancelot. En el momento de su muerte, lamentará esta desmesura.

El Tristan en prose nos da una de sus más negras imágenes. Tildado de traidor, de envidioso y cobarde (Löseth, 1891: $\$ 259, \$ 450$, $\$ 474$, etc.), su valentía ha declinado y su buena fama pertenece al pasado (Löseth, 1891, \$321); es considerado como uno de los peores caballeros del mundo (Löseth, 1891: \$184). Esta degradación del personaje suscita ciertas reticencias: en la mayor parte del manuscrito 772 de Löseth (manuscrito de la Biblioteca Nacional de París), una mano posterior raspó el nombre de Gauvain, cuando el héroe se encuentra en situación poco honrosa, para sustituirlo, generalmente, por el de su hermano Agravain (Löseth, 1891: 224-225, n. 1).

Al ser integrado, parcialmente, el Tristan en prose en la refundición del Lancelot-Graal del pseudo-Robert de Boron, fuente de diversas versiones italianas, de las españolas y de Malory, esta imagen degradada es la que llega a muchos de los autores posteriores.

Es interesante el tratamiento que Malory da a la figura de Gauvain. Pueden verse expresiones totalmente contradictorias como «he was a full noble knight as ever was born» $(21,8)$ frente a «after Sir Gareth had espied Sir Gawain's conditions, he withdrew himself from his brother Sir Gawain's fellowship, for he was vengeable, and where he hated he would be avenged with murder, and that hated Sir Gareth» $(7,34)$. No siempre es coherente Malory, como sin duda tampoco lo eran las fuentes en las que se basaba, procedentes de la fusión del Tristan en prose con el Lancelot-Graal. Existe un esfuerzo por conservar una cierta nobleza a la vieja figura, aunque resalta siempre su carácter vengativo. Además, no sólo en la parte correspondiente a la demanda del Graal - donde la espiritualización de las aventuras conllevaba la degradación del personaje- ocupa un lugar poco honroso como guerrero. Carece de fortuna en muchas de sus aventuras anteriores $(3,5-8 ; 4,27-28 ; 11,4)$, es considerado inferior a su hermano Gaheris [Guerrehès] $(9,42)$ y sobre todo a Gareth [Gaheriet]. Mata vergonzosamente a Pellinor [en esta versión padre de Perceval] $(11,10)$ y a Lamorak $(18,3 ; 19,11)$, toma a Ettard, conociendo el gran amor que el buen caballero Pelleas sentía por ella $(4,22)$, etc. Pese a todo, si no es el gran caballero de los poemas en verso, conserva una cierta dignidad al defender a Launcelot de las acusaciones de sus hermanos Agravain y Mordred, recordando que él lo había rescatado cuando Carados de la Torre Dolorosa lo retenía preso $(20,1)$. Unicamente la muerte de sus hermanos Ga- 
heris y Gareth producirá en él una sed insaciable de venganza contra el que había sido su amigo. Malory transmite pues, al final de la Edad Media, una imagen, en la mayoría de las ocasiones, poco halagüeña, sin llegar a la total degradación de algunos episodios del Tristan en prose. Por matar a Lamorak se presenta bajo la forma adversa del destructor de buenos caballeros.

\section{Características de Gauvain}

Esta evolución de Gauvain parece estar vinculada a ciertas características del personaje, que resumí (Yllera, 1991) en su grandeza arcaica, sus rasgos épicos y sus rasgos míticos. Toda aparición del nombre de Gauvain se acompaña, en general, de las formas de respeto mes sire, etc. ${ }^{13}$. Es el héroe en la plenitud, aquel que ya ha adquirido el renombre; de ahí que, a diferencia de otros héroes artúricos, no oculte su nombre ${ }^{14}$. Como rasgos épicos, que lo diferencian de los demás héroes artúricos, conviene recordar que posee un caballo que tiene un nombre, aparentemente un nombre formado sobre un nombre común puesto que va acompañado del artículo (Le Gringalet o Le Guingalet) ${ }^{15}$, que se le atribuyen unas infancias en las que se acumulan todos los elementos del mito tradicional del héroe y que, aunque defiende a numerosas doncellas y despierta gran admiración en ellas, no es un héroe enamorado. Carece de dama. Por último, Gauvain es el único héroe artúrico al que se atribuyen ciertos rasgos míticos. Las fuerzas del héroe, en numerosas obras, crecen hasta alcanzar su plenitud a mediodía ${ }^{16}$, lo que le confiere rasgos de héroe solar. Por otra

13 No aparece el tratamiento en Wace, que los rehuye. Acerca del empleo de messire, sire delante de un nombre propio, cf. Foulet, 1950. Lo considera moda lanzada por Chrétien. Añade que, en este autor, «Le procédé consiste justement à réserver à Gauvain une marque assez exceptionnelle de déférence. On ne le met pas au-dessus des autres, on se borne à lui témoigner ainsi une affection particulière et souriante, comme à un vieil ami» (22-23). Pero no cabe duda de que Gauvain es objeto de un respeto particular.

14 La ocultación del nombre del caballero es un motivo muy frecuente en la novela artúrica. Se ha dicho que este motivo se relacionaba, en último término, con la idea, muy extendida entre los pueblos primitivos, de que el desvelar el nombre de uno conlleva el ponerse bajo el dominio del otro (BRUCE, 1923: 208, n. 27).

15 Para Loomis el nombre derivaría del galés guin-calet «blanco y atrevido» $(1949,156-$ 159). El mismo autor señaló que, en diversos textos artúricos, aparece el regalo de un caballo blanco que un hada hace a su amante o protegido (1945: 188-189).

16 Existen divergencias acerca de la hora de máxima fuerza aunque parece que la versión más extendida es la que establece que sus fuerzas aumentan alcanzando su máximo a mediodía. 
parte, es el personaje al que se atribuyen más aventuras relacionadas con el otro mundo, como la aventura en el castillo de la Reina de las Blancas Trenzas en Le Conte du Graal de Chrétien de Troyes o las frecuentes alusiones a su falsa muerte (L'Âtre Périlleux, Mériaduc, Diu Krône, etc.).

Algunas de las características de la materia artúrica (aunque no exclusivas de ésta) pueden, en parte, explicar la evolución del personaje. Son esencialmente la movilidad de los motivos empleados, el principio de la reduplicación de los personajes y la sustitución de unos personajes por otros.

Como en el folclore, existe en la materia artúrica una constante emigración de los motivos de unos textos a otros, pudiendo variar o no su justificación, sus consecuencias y la función que tienen dentro de la economía del relato. Ante la imposibilidad de desarrollar satisfactoriamente esta cuestión, citaré únicamente un ejemplo muy conocido: las manchas de sangre en el lecho, que delatan la presencia del amante y pueden o no engañar acerca de la identidad de éste: aparecen en el Tristan de Béroul (ed. Payen, vv. 715-756), en el de Eilhart von Oberg (vv. 3909-3942), en Le Chevalier de la Charrette (vv. 4633-4911) o en el Tristan en prose, en este último caso referido a los amores de Tristan y la mujer de Segurades (ed. Curtis I, \$367-373) ${ }^{17}$.

Se ha podido decir que la reduplicación es uno de los rasgos típicos del héroe (el héroe doble). En todo caso, es el sistema empleado por Chrétien y otros autores medievales para construir sus novelas. Se contraponen dos personajes que emprenden la misma aventura; uno fracasa y el otro triunfa. En La Mule sans frein o en L'Âtre Périlleux se contraponen Keu y Gauvain; en Le Chevalier de la Charrette Gauvain y Lancelot, en Le Conte du Graal, Gauvain y Perceval. En todos los casos triunfa el personaje más moderno, lo que conlleva cierta degradación del más arcaico ${ }^{18}$, que ve reducido su carácter heroico.

Se habla de ellas en la Primera Continuación de Perceval, en el Merlin, en el Lancelot propre, en La Mort d'Arthur, en el Tristan en prose, en Malory, etc.

17 Una variante de este motivo consiste en que la dama se hiere para evitar que las manchas de sangre en las sábanas descubran la presencia del amante: aparece, por ejemplo, en el Tristan en prose (ed. Curtis II, $\S 532-533$ ), o bien los compañeros del amante lo hacen para que no pueda ser descubierto, como Walwan y sus demás compañeros en el Tristrant de Eilhart von Oberg (vv. 5285-5442). No pretendemos, ni mucho menos, agotar la enumeración del motivo en la novela artúrica: también aparece, por ejemplo, en Malory, en el encuentro de Launcelot con la reina (19, 3-6).

18 Evidentemente, hay que entender «más moderno» o «más arcaico», no con relación a su tradición legendaria anterior a la constitución de la materia artúrica conocida, sino según la importancia que presenta en los más antiguos textos de la serie escrita en latín o en francés: de este modo, Keu ocupa un lugar más destacado que Gauvain en Geoffrey y en Wace. Es el gran compañero de Arturo, junto a Bedoer, mientras que Gauvain pertenece a una generación más joven. 
En relación con la movilidad de los motivos está la sustitución de unos personajes por otros. Tomando el ejemplo de una aventura muy a menudo vinculada al personaje de Gauvain, el reto del caballero que propone que le corten la cabeza a condición de que el que lo haga se someta, en un plazo determinado, a la misma prueba, vemos cómo se atribuye a Gauvain en La Mule sans frein, Humbaut, Sir Gawain and the Green Knight, Diu Krône de Heinrich von dem Türlin, etc.; en cambio, en la Primera Continuación del Perceval se atribuye a Caradoc (ed. Roach I, vv. 3332-3568) y en el Perlesvaus a Lancelot $(2873-2923 ; 5766-5785 ; 6638-6733)$. Parecería que podría pensarse que era originariamente una aventura de Gauvain si no fuese porque, en el texto irlandés del Festín de Briciu (Markale, 1971a, 108-114), se presenta como una aventura de Cuchulainn. Es probable, pues, que Gauvain sustituyese a Cuchulainn como protagonista de esta aventura y más tarde fuese sustituido por Caradoc o Lancelot, según los textos ${ }^{19}$.

Algunas de estas sustituciones están atestiguadas: es evidente que Galaad sustituye a Perceval como héroe del Graal, ante la importancia creciente de Lancelot y el deseo de vincularlo a la demanda: será Galaad, el hijo de Lancelot que lleva el nombre originario del padre, el que en la Queste del SaintGraal logre la demanda, sustituyendo a Perceval, quien lo consigue en Robert de Boron o en el Haut Livre du Graal (con el nombre de Perlesvaus).

El personaje más reciente se convierte en el protagonista de una aventura antaño atribuida a un personaje más arcaico que, a menudo, sufre una degradación. La degradación de Gauvain en algunos textos se inscribe dentro de un proceso más amplio de progresiva degradación de los más antiguos personajes del mundo artúrico. Basta con citar muy brevemente el caso de Morgain y de Keu. Morgain presenta un carácter positivo en Le Chevalier au Lion, donde su papel se limita a proporcionar a la doncella el ungüento que curará a Yvain de su locura (v. 2949); en Le Bel Inconnu se cita entre las más bellas mujeres (v. 4349); etc. El personaje sufre una total degradación en el Lancelot-Graal. Odia a Guenièvre (Lancelot, I: 300 ) y retiene prisionero a Lancelot (Ibid, I: 348, V: 47-48); es la «desleal» Morgain, que denuncia los amores de Lancelot y Guenièvre a Arturo (Mort d'Arthur \$48-53). En Malory, su odio se concentra sobre Arturo, al que intenta asesinar, sustituyéndole la vaina de Excalibur, que impide a quien la lleva perder sangre $(2,11 ; 4,8-11,14), y$, sobre todo,

19 Bruce (1923 II, 103, n. 12) supuso la hipótesis inversa: Gauvain, héroe más conocido, podría haber sustituido a Caradoc en una aventura anteriormente vinculada a él. Creemos, sin embargo, que la aventura se atribuyó antes a Gauvain, según aparece en la mayoría de los textos. 
eviándole - como Deyanira a Hércules- el manto que mata a quien se lo pone $(4,15-16)^{20}$.

Tampoco el valiente y leal Keu de Wace, el gran compañero de Arturo, escapa a esta degradación. Chrétien de Troyes matiza su carácter: es noble, se nos dice, pero su gusto por la burla y el sarcasmo estorban a su valentía (Le Conte du Graal, ed. Lecoy, vv. 2791-2799). Su valor queda eclipsado por el de otros caballeros, como muestra su rotundo fracaso en la búsqueda de la reina en Le Chevalier de la Charrette, fracaso comparable al de La Mule sans frein o L'Âtre Périlleux. En La Vengeance Raguidel es bromista, maldiciente, fanfarrón y eterno detractor de las mujeres. Es posible que la ironía de Chrétien fuese más tarde mal interpretada, pero, sobre todo, su evolución se explica por la necesidad de crear un contrapunto a la aventura del héroe, establecer una doble quête, lo que supone el fracaso de uno de los dos personajes. La degradación de Keu alcanza su grado máximo en el Perlesvaus, donde Keu mata cobardemente al hijo de Arturo [Loholt], para arrebatarle la gloria de haber destruido al gigante Logrin, y se pasa al enemigo (4004-4012: 4902-4955: 6292-6393) o, también, en el neerlandés Walewein ende Keye (Gauvain y $\mathrm{Keu}$ ), una de las obras más tardías del ciclo (G. Paris, 1888: 84-86). En cambio, en Malory, sin ser un buen guerrero, tampoco cae en la traición.

Al intentar explicar la degradación de Gauvain, en algunos textos, se ha hablado del deseo del compilador del Tristan en prose de exaltar la fama de Tristan (P. Paris, Romans de la Table Ronde, V, 1877: 153, nota, etc.). Sin embargo, en esta obra se ensalzan muchos otros caballeros, entre otros el sarraceno Palamède. Se ha pensado que podría deberse al carácter moralizador de las novelas tardías (Weston, 1897: 10-11) pero la explicación no resulta convincente si se tiene en cuenta que se celebra la poco moral figura de Lancelot y que el Tristan en prose es menos moralizador que La Queste del Saint-Graal o el Perlesvaus. Se ha apuntado también que la finalidad de sus aventuras carece de elevación; sus esfuerzos no están ni al servicio del amor ni de Dios (Busby, 1980: 398) ${ }^{21}$.

${ }^{20}$ La maldad de Morgan [Morgain] se manifiesta en otras anécdotas de La Morte d'Arthur de Malory, como el aprisionamiento de Lanzarote $(11,4$, etc.), el intento de matar a su marido, Urien (IV,13), o el suplicio del agua hirviendo al que somete a una dama, por el único delito de ser considerada la más hermosa del país $(11,1)$, etc. Hay que señalar que, pese al odio de Morgan hacia Arturo, vendrá con otras reinas a recogerlo cuando está malherido $(21,5-6)$, siguiendo la tradición de la Mort d'Arthur francesa ( $\$ 193$ ). En ambas obras aparece alterado este elemento de Geoffrey de Monmouth y de Wace, por el que Arturo era llevado a la isla de Avalón (sin especificar que por Morgain), al hablar poco después de la tumba de Arturo.

21 Para Lamart (1980: 201) es difícil explicar las causas de este ensombrecimiento de la figura de Gauvain en el Tristan en prose: kLes intentions de l'auteur paraissent donc obscures. 
Pienso que la degradación de Gauvain se inscribe dentro de un proceso que abarca a las más arcaicas figuras, que desaparecen, como Bedoer, se degradan, como Keu, o pasan a ocupar un papel muy secundario, como Yder o Yvain (salvo, evidentemente, en las obras aisladas que toman a uno u otro personaje como protagonistas: Yder o Le Chevalier au lion de Chrétien de Troyes). Gauvain era un personaje muy conocido, cargado de un rica simbología, que se sustituye por nuevas creaciones; durante un tiempo sirve de contrapunto para esos nuevos héroes, que acaban superándolo.

\section{ConClusión}

Personalidad demasiado rica para adaptarse al nuevo código cortés, Gauvain es sustituido por otros personajes más modernos: Lancelot y tal vez Perceval, que toman probablemente aventuras anteriormente atribuidas a él. Las fuerzas de origen mítico de Gauvain se sustituyen por la fuerza nacida del amor. Esta evolución se inicia, al menos, con Chrétien de Troyes: el héroe mítico y épico no puede encarnar la nueva figura del fin amant.

Todavía será el protagonista de numerosos poemas en verso y de la Primera Continuación del Perceval pero en las nuevas creaciones en prosa sufre un progresivo proceso de degradación (todavía no patente en el Perlesvaus). No es raro que culmine su degradación, dentro del mundo medieval francés, con el Tristan en prose, donde la caballería está totalmente vinculada al amor. No se debe, sin embargo, su degradación, en este texto, a su ausencia de amor, puesto que la obra contempla con ojos favorables a Dinadan, poco amigo del amor y consciente de los males que acarrea. Diríase, más bien, que recibe el reflejo del carácter negativo que, desde Geoffrey de Monmouth, tenía Mordret, su hermano o hermanastro, causante de la destrucción del reino.

En cambio, en Sir Gawain and the Green Knight sufre un proceso inverso, de total espiritualización, como el Galaad de la Queste del Saint-Graal. Uno de los aspectos más admirables de este poema es su habilidad para inte-

\footnotetext{
Pourquoi avoir déshonoré celui que la tradition regardait comme le meilleur chevalier du monde? Est-ce conception pessimiste de l'homme chez un écrivain qui avilit Marc et révèle en Tristan bien des sentiments bas? Est-ce jugement négatif sur les chevaliers si corrompus par le siècle qu'ils sont perdus sans espoir? De même qu'Alcuin déplorait la supériorité morale d'illustres païens, pourtant privés de la révélation, l'auteur du Tristan en prose en inventant Palamède montrait qu'un païen pouvait être plus vertueux et plus pur que n'importe quel chevalier chrétien».
} 
grar, mediante el motivo de la tentación, el mundo más espiritualmente cristiano con los elementos míticos vinculados a Gauvain, como el reto de la decapitación.

Gauvain, el héroe cuya trayectoria es el caminar hacia su progresiva degradación (en las versiones en prosa que acaban predominando sobre los viejos poemas en verso), es probablemente el único auténtico héroe -en sentido pleno- del ciclo artúrico, si excluimos a Arturo. Chrétien - uno de los primeros creadores de la novela occidental (en cuanto distinta de la épica)orienta el género en un sentido de racionalidad y cotidianidad, que lo aleja del mundo heroico propiamente tal. El que instala el tema artúrico en la literatura occidental $^{22}$, rehusa tomar como protagonista a Gauvain, una de sus principales figuras heroicas. Al relegarlo progresivamente a un incómodo segundo plano, al investir con sus aventuras a nuevos personajes, lo condena a una progresiva degradación. A partir de Chrétien de Troyes, cuando se habla de «héroe» referido al mundo artúrico, el término se utiliza en su sentido "aminorado» (o «degradado»).

22 Geoffrey de Monmouth o Wace componen obras más cercanas a los «anales», a la «historia», por legendaria que sea, que a la novela o a la literatura. 


\section{BIBLIOGRAFÍA}

OBRAS

Âtre Périlleux (L'), ed. B. Woledge, París, Champion, C.F.M.A., 1936. Trad. esp. Madrid, Siruela.

Béroul, Tristan, *ed. E. Muret, L.M. Defourques, París, Champion, C.F.M.A., 1974; Les Tristan en vers, ed. y trad. al fr. mod. de J. Ch. Payen, París, Garnier, 1974. Trad. esp. de R. Ruiz Capellán, Madrid, Cátedra, 1985.

Continuations du «Perceval»:

- Primera, ed. W. Roach, 3 vol., 4 t. (léxico de L. Foulet), Philadelphia, Univ. of Pennsylvania - The American Philosophical Society, 1949-1955. Trad. al fr. mod. (a partir de la ed. de Ch. Potvin) de Henri de Briel, París, Klincksieck, 1972.

Chevalier à l'épée (Le), ed. R.C. Johnston y D.D. R. Owen, Two Old French Gauvain Romances, Edimburgo y Londres, Scottish Academic Press, 1972.

Chrétien de Troyes, Erec et Enide, *ed. M. Roques, París, Champion, C.F.M.A., 1970. Trad. al fr. mod. París, Champion; de A. Mary, París, Gallimard, 1966. Trad. al esp. de C. Alvar, V. Cirlot y A. Rossell, Madrid, Editora Nacional, 1982; Madrid, Siruela, 1987.

- Cligès, ed. A. Micha, Paris, Champion, C.F.M.A., 1978.

- Le Chevalier de la Charrette, *ed. M. Roques, París, Champion, C.F.M.A., 1970. Trad. al fr. mod. de J. Frappier, 2." ed., París, Champion, 1977. Trad. esp. de C. García Gual y L. Alberto de Cuenca, Barcelona, Labor, 1976; Madrid, Alianza Ed., 1983. 
- Le Chevalier au Lion (Yvain), *ed. M. Roques, París, Champion, C.F.M.A., 1971. Trad. al fr. mod. de A. Mary, París, Gallimard, 1966. Trad. esp. de M.-J. Lemarchand, Madrid, Siruela, 1984.

- Le Conte du Graal (Perceval), *ed. F. Lecoy, París, Champion, C.F.M.A., 1975; ed. W. Roach, Ginebra, Droz, T.L.F., 1959. Trad. esp. de M. de Riquer, Madrid, Espasa-Calpe, 1961; Barcelona, El Festín de Esopo, 1985.

EILHART von OBERG, Tristrant, ed. diplomática de los manuscritos y trad. al fr. mod. de D. Buschinger, Goppinger, 1976 (Goppinger Arbeiten zur Germanistik, 202); trad. al fr. mod. de D. Buschinger y W. Spiewok, París, U.G.E., 10/18, 1986.

Enfances Gauvain (Les), ed. P. Meyer, Romania 39 (1910), 1-32.

Estoire de Merlin, ed. O. Sommer, The Vulgate Version of the Arthurian Romances, $\mathrm{t}$. II, Washington, The Carnegie Institution, 1909.

Estoire del Saint Graal, ed. O. Sommer, The Vulgate Version of Arthurian Romance, t. I., Washington, The Carnegie Institution, 1909.

Gawain and the Green Knight (Sir), *ed. y trad. fr. de E. Pons, París, Aubier, Editions Montaigne, 1945. Trad. ingl. mod. de B. Stone, Londres, Penguin Books, 1974.

Geoffrey de Monmouth, Historia regum Britanniae, ed. A. Faral, en La Légende Arthurienne. Etudes et Documents, t. III, París, Champion, 1929. Trad. esp. de L. A. de Cuenca, Madrid, Siruela, 1987.

GotTrRied von Strassburg, Tristan, ed. K. Marold, Berlín, Nueva York, 1977. Trad. esp. de B. Dietz, Madrid, Editora Nacional, 1982 (otra trad. en Siruela).

Le Haut Livre du Graal. Perlesvaus, *ed. W. A. Nitze y T. Atkinson Jenkin, 2 vol., Chicago, Univ. of Chicago Press, 1932-1937 (repr. Nueva York, Phaeton, 1972). Trad. esp. de V. Cirlot, Madrid, Siruela, 1986.

Hunbaut, ed. J. Stürzinger y H. Breuer, Dresden, Max Niemeyer, 1914.

Jean, Les Merveilles de Rigomer, ed. W. Foerster, 2 vol. Dresden, Max Niemeyer, 1908.

Malory, Sir Thomas, Le Morte d'Arthur, *ed. J. Cowen, intr. de J. Lawlor. 2 vol., nueva ed., Londres, Penguin Books, 1987. Trad. esp. de F. Torres Oliver, 3 vol. Madrid, Siruela, 1985. 
Marie de France, Lais, *ed. J. Rychner, París, Champion, 1966. Trad. al fr. mod. de P. Jonin, París, Champion, 1977. Trad. esp. de A. M." Valero de Holzbacher, Madrid, Espasa-Calpe, 1978. (Otra trad. en Siruela).

Lancelot en prose, *ed. A. Micha, 8 vol., Ginebra, Droz, T.L.F., 1978-1982 y O. Sommer, The Vulgate Version of Arthurien Romances, t. III-V, Washington, The Carnegie Institution,1910-1912. Trad. fr. mod. parcial de A. Micha, Lancelot, 2 vol., París, U.G.E., 10/18, 1983-1984.

Merlin Huth, *ed. G. Paris y J. Ulrich, 2 vol., París, S.A.T.F., 1886. Trad. al fr. mod. de H, de Briel, París, Klincksieck, 1971; trad. al fr. mod. parcial de E. Baumgartner, París, Stock, 1980. (La edición de G. Paris y J. Ulrich contiene el Merlin Huth y la versión en prosa del poema de Robert de Boron).

Mort le Roi Artu (La), *ed. J. Frappier, Ginebra, Droz, T.L.F., 1936. Trad. esp. de C. Alvar, Madrid, Alianza Tres, 1980.

Mule sans frein (La), ed. R.C. Johnston y D.D. R. Owen, Two Old French Gauvain Romances, Edimburgo y Londres, Scottish Academic Press, 1972.

Queste del Saint Graal (La), *ed. A. Pauphilet, París, Champion, C.F.M.A., 1923. Trad. al fr. mod. de A. Béguin, París, Seuil, 1965; de E. Baumgartner, París, Champion, 1979. Trad. esp. de C.Alvar, Madrid, Editora Nacional, 1980.

RaOul De Houdenc, La Vengeance Raguidel, ed. M. Friedwagner, Sämtliche Werke II, Halle a.s., Max Niemeyer, 1909.

Renaut de Beaujeu, Le Bel Inconnu, *ed. G. Perrie Williams, París, Champion, C. F.M.A., 1929. Trad. esp. de V. Cirlot, Madrid, Siruela, 1983.

Robert Biquet, Lai du Cor, ed. H. Dörner, Estrasburgo, Druck von M. SuMont Schauberg, 1907.

ROBERT DE Boron, Joseph d'Arimatie, ed. W. A. Nitze, en Le Roman de l'Estoire dou Graal, París, Champion, C.F.M.A., 1927 (versión en verso).

- Merlin, ed. W.A. Nitze, Ibid. (fragmento en verso), ed. A. Micha, Ginebra, Droz, T.L.F., 1979 (versión en prosa).

- Didot-Perceval, ed. W. Roach, Philadelphia, Univ. of Pennsylvania Press,1941. (repr. Ginebra, Slatkine, 1977).

- Edición de la versión en prosa de la trilogía, B. Cerquiglini, Le Roman du Graal, París, U.G.E., 10/18, 1981. 
Romans de la Table Ronde mis en nouveau langage et accompagnés de recherches sur l'origine et le caractère de ces grandes compositions par P. Paris, 5 vol. París, L. Techener, 1868-1877.

ThOMas, Tristan, *ed. y reconstrucción de las partes perdidas de J. Bédier, Le Roman de Tristan, 2 vol. París, Firmin Didot, S.A.T.F., 1902-1905; ed. de las partes conservadas B.H. Wind, Ginebra, Droz, T.L.F., 1960.

Tristan en prose, ed. R. L. Curtis, I, Munich, Max Hueber Verlag, 1963, II, Leyden, E. J. Brill, 1976; III, Cambridge, 1985; Ph. Ménard, I, Ginebra, Droz, T.L.F., 1987; J. Blanchard, Le «Roman de Tristan en Prose». Les deux captivités de Tristan, Paris, Klincksieck, 1976.

WACE, La Partie Arthurienne du Roman de Brut, ed. I. D. O. Arnold y M. M. Pelan, París, Klincksieck, 1962.

\section{ESTUDIOS}

ACKerman, R.W. (1959). "The English Rimed and Prose Romances», en R.S. Loomis (ed.) Arthurian Literature in the Middle Ages, pp. 480-519.

ANDrew, M (1979), The «Gawain-Poet». An Annotated Biblioqraphy. 1839-1977, Nueva York \& Londres, Garland Publishing Inc.

Atanassov, St. (1984), «Gauvain: malheur du nom propre et bonheur du récit», en D. Coste \& M. Zéraffa (eds.), Le Récit amoureux. Colloque de Cerisy-la-Salle, Seyssel, Champ Vallon, pp. 11-21.

BarRoN, W.R.J. (1973), «French Romance and the Structure of Sir Gawain and the Green Knight», en Studies in Medieval Literature and Languages in Memory of Frederick Whitehead, Manchester Univ. Press, pp.7-25.

Baudouin, Ch. (1952), Le Triomphe du héros. Etude psychanalytique sur le mythe du héros et les grandes épopées, París, Plon.

Bogdanow, F. (1973), «The Transformation of the Role of Perceval in some Thirteenth Century Prose Romances», en Studies... in Memory of Frederic Whitehead, pp. 47-65. 
Bianchini, S. (1973), «Due brevi romanzi di Chrétien de Troyes?», en Cultura Neolatina 33, pp. 55-68.

BruCE, J. D. (1923-1924), The Evolution of Arthurian Romance from the Beginings down to the year 1300, 2 vol., Göttingen, Vandenhoek \& Ruprecht - Baltimore, The Johns Hopkins Press. (Reimpr. de la ed. de 1928, Ginebra, Slatkine, 1974).

BusBy, K. (1980), Gauvain in Old French Literature, Amsterdam, Rodopi.

Buchanan, A. (1932), «The Irish Framework of Gawain and the Green Knight», P.M.L.A. 47, pp. 315-338.

Campbell, J. (1959), El Héroe de las mil caras. Psicoanálisis del mito, trad. esp., México, F.C.E.

Cross, T. P. (1915), «The Celtic Elements in the Lays of Lanval and Graelent», Modern Philology 12, pp. 585-644.

Charvet, L. (1967), Des «Vaus d'Avalon» à la "Queste du Graal», París, J. Corti.

Duval, A. (1838), «Petits poèmes épisodiques tirés de l'histoire d'Artus et de ses chevaliers», en Histoire littéraire de la France, París, Firmin Didot \& Treuttel \& Wortz, pp. 704-729.

FARAL, Ed. (1929), La Légende Arthurienne. Etudes et documents, 3 vol., París, Champion.

FOULET, L. (1950), «Sire, messire», Romania 71, pp. 1-48, 180-221.

FrapPIER, J. (1957), Chrétien de Troyes. L'homme et l'oeuvre, Paris, Hatier - Boivin.

- (1958), «Sur la composition du Conte del Graal», Le Moyen Age 64, pp. 67-102.

- (1960), «Note complémentaire sur la composition du Conte del Graal», Romania 81 , pp. $308-337$.

- (1972), Chrétien de Troyes et le mythe du Graal, París, S.E.D.E.S.

GaRcfa Gual, C. (1983), Historia del rey Arturo y de los nobles errantes caballeros de la Tabla Redonda, Madrid, Alianza Ed.

Gautier, L. (1891), La Chevalerie, nueva ed., París, Librairie Charles Delagrave.

HaIdu, P. (1968), Aesthetic Distance in Chrétien de Troyes: Irony and Comedy in "Cligès» and "Perceval", Ginebra, Droz. 
HULBERT, J. R. (1915-1916), «Syr Gawayn and the Grene Knyght», Modern Philology 13, pp. 433-462, 689-730.

ImBS, P. (1950-1952), «Perceval et le Graal chez Chrétien de Troyes», Bull. de la Soc. Académique du Bas-Rhin 72-74, pp. 38-79.

Johnston, R.C. (1978), «The Autorship of the Chevalier and the Mule», The Modern Language Review 73, pp. 496-498.

KeLly, D. (1969), «Multiple Quests in French Verse Romance Merveilles de Rigomer and Claris et Laris», L'Esprit Créateur 9, pp. 257-266.

Kellermann, W. (1956), «Le Problème de Bréri», en Les Romans du Graal aux XIIe et XIlle siècles, París, Ed. du C.N.R.S., pp. 137-148.

KitTREDGE, G. L. (1916), A Study of "Gawain and the Green Knight», Cambridge, Harvard Univ. Press.

KOHLER, E. (1974), L'Aventure chevaleresque. Idéal et réalité dans le roman courtois, trad. fr., París, Gallimard.

LamarT, J. (1980). «Le Personnage de Gauvain dans quelques romans arthuriens du $\mathrm{XII}^{e}$ et du XVIII ${ }^{e}$ siècle», en Etudes de Langue et de littérature française offertes à André Lanly, Nancy, Univ. de Nancy, pp. 185-202.

Le Rider, P. (1978), Le Chevalier dans le "Conte du Graal» de Chrétien de Troyes, París, S.E.D.E.S.

Loomis, R. Sh., (1945), «Morgain la Fée and the Celtic Goddesses», Speculum 20, pp. 183-203.

- (1949), Arthurian Tradition \& Chrétien de Troyes, Nueva York, Columbia University Press.

- (1958), «Objections to the Celtic Origin of the Matière de Bretagne», Romania 79, pp. 47-77.

- (1959), ed., Arthurian Literature in the Middle Ages. A Collaborative History, Oxford, Clarendon Press.

LOSETH, E. (1891), Le Roman en Prose de Tristan. Le Roman de Palamède et la Compilation de Rusticien de Pise. Analyse critique d'après les manuscrits de Paris, $\mathrm{Pa}-$ rís, Emile Bouillon.

Markale, J. (1971a), L'Epopée celtique d'Irlande, Paris, Payot. 
- (1971b), L'Epopée celtique en Bretagne, París, Payot.

MARX, J. (1952), La Légende arthurienne et le Graal, París, P.U.F.

- (1959), "La Quête manquée de Gauvain», Mélanges offerts à Etienne Gilson, Toronto, Pontifical Institute of Medieval Studies - París, Vrin, pp. 415-436.

MerTENS-FoncK, P. (1969), «Morgan, fée et déesse», en Mélanges Rita Lejeune, II, Gembloux, Duculot, pp. 1067-1076.

Micha, A. (1978), «Romans dont Gauvain est le héros», en H.R. Jauss \& E. Köhler (eds.), Grundriss der Romanischen Literaturen des Mittealters, IV, 1, Heidelberg, Carl Winter, pp. 380-387.

Nitze, W.A. (1902), The Old French Grail Romance «Perlesvaus». A Study of its Principal Sources, Baltimore, John Murphy Co.

NUTT, A. (1888), Studies on the Legend of the Holy Grail with Especial Reference to the Hypothesis of its Celtic Origin, Londres, Publications of the Folk-Lore Society.

NYKROG, P. (1979), «Trajectory of the Hero: Gauvain paragon of Chivalry 1130-1230», en Medieval Narrative. A Symposium H. Bekker-Nielsen et al. (eds.), Odense Univ. Press, pp. 82-93.

OWEN, D.D.R. (1968), The Evolution of the Grail Legend, Edimburgo \& Londres.

- (1971), «Two more Romances by Chrétien de Troyes?», Romania 92, pp. 246-260.

ParIS, G. (1881-1883), Etudes sur les Romans de la Table Ronde. I. Lancelot du Lac (I. Le «Lanzelet" d'Ulrich de Zatzikhoven. II. «Le Conte de la Charrette»), París, Nogent-le-Rotrou (extracto de Romania, 1881-1883).

- (1888), "Romans épisodiques», en Histoire littéraire de la France, XXX, París, Imprimerie Nationale, pp. 29-103.

Rank, O. (1983), Le Mythe de la naissance du héros. Suivi de La Légende de Lohengrin, París, Payot.

Riquer, M. de (1957), «Perceval y Gauvain en Li Contes del Graal», Filologia Romanza 4, pp. 119-147.

- (1957-1958), «La Composición de Li Conte del Graal y el Guiromelant», Boletín de la Real Academia de Buenas Letras de Barcelona 27, pp. 279-320.

SAvATER, F. (1982), La Tarea del héroe. (Elementos para una ética trágica), Madrid, Taurus. 
SPARNAAY, H. (1959), «The Dutch Romances», en R.S. Loomis (ed.), Arthurian Literature in the Middle Ages, pp. 443-461.

Thomas, M. C. (1883), Sir Gawayne and the Green Knight. A Comparison with the French Perceval..., Zurich, Orell Fussli \& Co.

Vial, G. (1987), "Le Conte du Graal». Sens et unité. La Première Continuation. Textes et contenu, Ginebra, Droz.

Weston, J.L. (1897), The Legend of Sir Gawain. Studies upon its Original Scope and Significance, Londres, David Nutt, Grimm Library 7.

- (1901), The Legend of Sir Lancelot du Lac. Studies upon its Origin, Development, and Position in the Arthurian Romantic Cycle, Londres, David Nutt, Grimm Library 12 .

- (1906-1909), The Legend of Sir Perceval. Studies upon its Origin, Development, and Position in the Arthurian Cycle, 2 vol., Londres, David Nutt, Grimm Library $17 \& 19$.

YLLERA, A. (1991), "Gauvain/Gawain: las múltiples transposiciones de un héroe», $R e$ vista de literatura medieval 3, pp. 199-221. 